This case is instructive in showing the necessity for thorough social investigation, and also because it demonstrates how misguided would have been the alternative measure of invaliding such a man on the grounds of his dyspepsia.

\section{Methods of Investigation}

The inquiry into the circumstances and the treatment of such cases is by no means easy: under the existing system the divisional officer is responsible to his captain for the individual welfare of his men; this responsibility is shared to some extent by the chaplain in a big ship or at a shore base. That more men do not go sick from this cause under the exacting conditions of Naval service is a tribute to the efficiency of the system as much as to the stability of the men themselves. The introduction of airgraph letters and cheap cable rates has undoubtedly done much towards allaying the anxiety of men on foreign stations; nevertheless there does seem to be a need for a more specialized branch of social welfare organization to which complex and difficult cases could be referred, especially by the psychiatric specialists in depots, where such cases are usually first seen.

Much can be done, and is being done, by the existing welfare societies, but, since in peacetime it has been found necessary to employ specially trained workers in this field, the need can scarcely be less great in wartime. It is sometimes objected that the Englishman will not tolerate interference in his private affairs, but this prejudice is not borne out by personal experience or by the records of the psychiatric social services. The epic success of a follow-up of $\mathbf{1 0 0}$ families in which both parents had committed suicide marks a high level of achievement, and is a tribute to the workers who carried it out without a single tebuff. The growing demand for trained psychiatric social workers in clinics and voluntary hospitals is an indication that this kind of work is needed and can be effective.

It is possible that a further expansion of the social servicesas, for example, by the appointment of a psychiatric social worker to Naval depots-might lead to a reduction in the invaliding rate from this cause. The work of the psychiatrists in hospitals and barracks would be greatly helped by such an arrangement, and it seems possible that the executive branch might also welcome assistance in carrying out what must be a difficult and time-consuming part of their duties.

\section{Summary}

The role of domestic difficulties in causing nervous breakdown in the Navy is compared with that of other aetiological factors; special note is made of the bad prognosis in these cases and in those in which there are multiple causal factors. The various types of home worry and the possible causes of its virulence are discussed. The need for thorough investigation is illustrated, and a suggestion is put forward for the enlistment of the services of psychiatric social workers to supplement the existing arrangements.

\section{REFERENCES}

Beaton, T. The Naval Medical History of the War, Admiralty, London. Wextbok of Medical Psychology, tr. El, 1, 305. B. Strauss, London.

\section{THE TONIC ACTION OF STRYCHNINE}

\section{W. F. ANDERSON, M.D.}

(From the Department of Materia Medica and Therapeutics, University of Glasgow, and Stobhill Hospital, Glasgow)

Strychnine is often used as the principal constituent of tonic mixtures. This custom is in part dependent on the belief that in therapeutic doses this drug has a beneficial action on the gastro-intestinal tract, promoting the appetite, rendering the digestive processes more efficient, and thereby increasing weight and general well-being. Strychnine, of course, in virtue of its taste has the action associated with simple bitters which reflexly increases the appetite and the flow of gastric juice. Therefore, in order to determine whether strychnine has any effects other than those due to the taste the drug should be given parenterally.

\section{Experimental Findings}

The present research was carried out with the view of finding whether strychnine administered parenterally had any action on gastric digestion and whether any evidence could be obtained in support of its use as a tonic.

Effect of a Single Dose of Strychnine on the Secretion of the Fasting Stomach.-Four specimens of fasting juice were aspirated at 15-minute intervals. Thereafter $1 / 20 \mathrm{gr}$. of strychnine was injected subcutaneously and the juice again withdrawn during the succeeding hour. In four subjects with normal gastric acidity there was an increase both in the volume and in the hydrochloric acid content of the gastric juice after administration of the drug. In three patients with achlorhydria the strychnine failed to stimulate the secretion of hydrochloric acid or to alter significantly the volume of the secretion.

Effect of a Singie Dose of Strychnine on the Movements of the Fasting Stomach.-Bennett (1923) stated that small doses of strychnine had a beneficial effect on gastric atony, and quoted Berti to show that as small a dose as $0.5 \mathrm{mg}$., given orally. caused increased gastric peristalsis. Dickson and Wilson (1925) also maintained that strychnine increases gastric motility. Bastedo (1936) stated that it increased the height of the hunger contractions. Clark (1940), on the other hand, affirmed that strychnine had no effect on gastric movements even when given in large doses. In the present investigation $1 / 20 \mathrm{gr}$. of strychnine hydrochloride was given after a period of at least five hours without food or water. Gastric motility was recorded by a modification of Carlson's balloon method (Anderson, 1943). In eight subjects the strychnine was given during a period of quiescence, and in each of them strong gastric contractions appeared after an interval of 5 to 15 minutes, and lasted from 20 to 45 minutes. The movements so produced were strong. and the interval between each wave tended to become shorter towards the end of the period of contractions. In two subjects the strychnine was given after a period of contractions had lasted 35 and 45 minutes respectively; in each case a prolonged period of quiescence followed the administration of the drug. The quiescent phase may have been due to fatigue of the gastric muscle.

Effect of Continued Administration of Strychnine on the Response of the Gastric Secretions to a Test Meal.-The subjects of this investigation were 2 men with a slight degree of hyperchlorhydria and 5 with achlorhydria. Strychnine hydrochloride gr. 1/30 was given subcutaneously three times daily for three to four weeks. Test meals were given before and at the end of the period of strychnine medication. In one patient with hyperchlorhydria the maximum percentage of hydrochloric acid was reduced, while in one achlorhydric a small amount of free hydrochloric acid appeared. In no other patient was there any significant change in the secretion of acid. In four subjects the emptying-time was shortened, while in the other three it was unaltered.

Effect of Subcutaneous Administration of Strychnine on the Weight and General Condition.-Ten patients convalescing from various types of illness were employed for this investigation. In all, the weight had been stationary for three weeks before the drug was given. In addition the haemoglobin had been estimated together with the red and white cell counts. The strychnine was given subcutaneously in doses of $2.9 \mathrm{mg}$. three times daily for periods of 14 to 28 days. All the patients were on full ward diet and were all encouraged to eat as much as they desired. There were no significant changes in either the haemoglobin percentage or the cell content of the blood. Five patients showed an increase in weight of 1 to $5 \mathrm{lb}$., while in three patients there was a decrease of $1 \mathrm{lb}$. and in two there was no alteration.

Effect of a Single Injection of 1/20 gr. of Strychnine on the White Blood Cells.-Sollmann (1936) states that in vitro phagocytosis is hindered by very large doses of strychnine. while Edmunds and Lloyd (1923) find an increase in the white cells in healthy dogs. In two patients who received a subcutaneous injection of $1 / 20$ gr. of strychnine no significant change in the number or distribution of white cells was noted.

\section{Summary}

From these investigations on strychnine three positive findings emerge: this drug appears, first, to stimulate the fasting stomach to active contractions; secondly, in some cases to hasten the emptying-time after a test meal; and, thirdly, to increase the volume and acidity of the fasting gastric juice. No evidence has been here 
adduced to indicate that the parenteral administration of strychnine leads to any improvement in the general condition of the patient.

I should like to express my indebtedness to Prof. Noah Morris for his help, and to the Medical Research Council for a grant cowards expenses.

REFERENCES

Anderson, W. F. (1943). Lancet, 1, 40.

Bastedo, W. A. (1936). J. Amer med. Ass., 106, 85.

Bennett, T. I. (1923). British Medical Journal, 1, 366

Applied Pharmacology. London.

Dickson, W. H., and Wilson, M. J. (1925). J. Pharmacol., 24, 33.

A Manual of Pharmacology, Philadelphia.

\section{Medical Memoranda}

\section{Mechanical-lung Treatment of Pneumonia complicating Acute Poliomyelitis}

The following case is reported because of the excellent results obtained by using the mechanical lung in the treatment of pneumonia in a patient who was almost moribund.

\section{Case History}

The patient was admitted to hospital on Aug. 22, 1943, as a transfer from another hospital. His history up to that time is described from the notes which accompanied him and from his own observations.

On the morning of Aug. 20 the patient; a warrant officer aged 25, reported sick with a severe headache. By evening his headache was very bad, he had developed pains in the back, and he felt feverish. On admission to hospital he was found to have coarse rhonchi in the left base of the chest and also a few rales; there was no dullness. He was ordered sulphapyridine 2 g., four hours later $2 \mathrm{~g}$., and then $1 \mathrm{~g}$. four-hourly. The next morning he complained of pain in the back, pains down the front of his thighs, and weakness. His eyes were suffused. By evening the signs in his chest had subsided and he was taken off sulphapyridine, having received $8 \mathrm{~g}$. Headache was slight at the time and he had no bodily pains. In the afternoon he had attempted to get out of bed, but found he could not do so, although he could sit up. Next morning he could neither sit up nor move his lower limbs. Knee- and ankle-jerks and superficial abdominal reflexes were absent. He was transferred to this hospital as a case of acute anterior poliomyelitis.

Aug. 22.-Examination showed a young man of anxious expression and very apprehensive, well nourished, and well developed; his face was a little cyanosed. At 2 p.m. his temperature was $101^{\circ}$, pulse 60 , and respirations 26 ; breathing was entirely diaphragmatic. Abnormalities in muscle power and reflexes were: left and right triceps and right serratus magnus flaccid; deltoids moderately strong; pectorals and biceps strong; biceps reflexes brisk; intercostals and abdominal muscles flaccid; superficial abdominal reflexes absent; back and buttock muscles flaccid; thighs flaccid; knee-jerks absent; slight power in left gastrocnemius, right flaccid ; ankle-jerks absent; moderate power in left tibialis anticus and peronei; slight power in right anticus and peronei; plantar reflexes flexor. Muscles were not tender, and there were no abnormalities of sensation. Paresis of the bladder was present, and the sphincters were continent. His white cell count was 10,800 per c.mm.--polymorphonuclears $82 \%$. The cerebrospinal fluid contained increased globulin, 15 cells per c.mm.- polymorphs - and was sterile. The only other finding was diminished breath sounds at the right base, posteriorly.

Aug. 23.-T. at 6 a.m. $101.6^{\circ}$. Catheterized twice; vomited twice.

Aug. 24.-T 99.4 , P. 70, R. 24 at 10 a.m. Was more cyanosed Percussion note dull at right base posteriorly and V.F. increased. Breath sounds faint over right posterior lower third of chest; no adventitious sounds. Apex beat not displaced. Partial collapse of right lower lobe-liver's interference with diaphragmatic action considered the probable cause. The head of the bed was raised.

Aug. $25 .-$ T. $102.8^{\circ}$, P. 86, R. 36 at 6 a.m. Further cyanosed Chest signs unchanged. Radiograph of chest showed opacity of irregular density of right lower third, with some mottling of middle third and increased right hilar shadows. Lobar pneumonia, right lower lobe, diagnosed. Fowler position adopted and $2 \mathrm{~g}$. of sulphathiazole given, to be followed by $1 \mathrm{~g}$. four-hourly.

Aug. $26 .-$ T. $99^{\circ}$, P. 100 , R. 36 at 6 a.m. At 6 p.m. his general condition was worse and he looked a bad colour. Bubbling rales could be heard at some distance and he was unable to cough. Some viscid sputum from time to time collected at the back of his throat and was swabbed out of his mouth. When passing through the larynx it caused considerable respiratory distress, and on two occasions he vomited, bringing up sputum. Respirations 46, shallow and jerky. Oxygen given by nasal catheter. At 11 p.m. was mildly delirious and looked gravely ill.

Aug. 27.-At 2 a.m. he was delirious and ashen in colour. There were loud bubbling rales, and a rattle in his throat. $P .140, R$. 44 . He was placed in the mechanical lung, head end raised on 9-in. blocks. (The respirator had been completed by the Military Engineering Service only three hours earlier, they having done the job in a day.) At 5 a.m. there was a dramatic improvement. Cyanosis was slight, pulse 92 , and orientation normal, though the patient was apprehensive of the lung and wanted to be taken out. Breathing was quiet and no rales could be heard. The lung was working at 25 respirations a minute and at pressures of $-14 \mathrm{~cm} . \mathrm{H}, \mathrm{O},+4 \mathrm{~cm}$ H.O. At 8 a.m. the patient was removed from the lung to be catheterized and made comfortable. $R, 36, P, 116$ after 10 minutes, and cyanosis returning. Replaced in lung after half an hour, and pulse soon settled to 96 a minute.

From this time on he made good progress and finally left the mechanical lung on Sept. 8. On Oct. 1 his paralysis remained much as on admission, except that the upper-arm muscles were much weaker. His bladder function returned on Sept. 1.

The striking effect of the mechanical lung was the change it produced in the chest-from a "bubbling cauldron" to quiet breathing; for no rales were audible after 8 a.m. on Aug. 27.

In am indebted to Col. C. H. N. Baker, Officer Commanding, for permission publish this case.

$$
\begin{aligned}
& \text { Combined Indian Military Hospital, } \\
& \text { India Command. }
\end{aligned}
$$

\section{Tuberculous Infection of an Extrapleural Pneumothorax complicated by Gl. welchii Infection}

It may be of interest to record a case of pulmonary tuberculosis in which a tuberculous effusion in an extrapleural pneumothorax was sterilized by the use of "azo-T." Subsequent infection by $\mathrm{Cl}$. welchii was successfully treated by azo-T lavage and sulphathiazole instillations.

\section{Case History}

A woman aged 35 had been treated for bilateral pulmonary tuberculosis since June, 1939, by extrapleural pneumothorax on the right and intrapleural pneumothorax on the left, the latter being abandoned in Feb., 1942. The right extrapleural pneumothorax was satisfactory until Oct., 1941, when fluid first appeared. In Dec., 1941 , the fluid was thin, straw-coloured, and lymphocytic, and contained scanty tubercle bacilli. In Nov., 1942, the character of the fluid had changed; it was then muco-purulent, polymorphic, and there were numerous tubercle bacilli.

Out-patient treatment by aspiration and injection of azochloramide and sodium-tetradecyl sulphate on the lines recommended by Petrof (Amer Rev. Tuberc., 1941, 44, 738) was instituted on Jan. 19, 1943. Aspirations were at first carried out on alternate days and later twice weekly. The fluid gradually became thinner, and the number of tubercle bacilli decreased until on Feb. 22 no bacilli were present. The fluid remained thin for the next three weeks, but pus cells were persistent. On March 16 the presence of fungal hyphae was noted and culture of the fluid gave a moderate growth of Penicillium glaucum. This persisted in the next two specimens. On March 22 the patient complained of pain in the right side of the chest, and her temperature was $100^{\circ} \mathrm{F}$. Her general condition was quite good, but in view of her symptoms she was admitted to hospital. Aspiration was performed on the same day, and next day the bacteriologist reported the presence of $\mathrm{Cl}$. welchii in large numbers. $\mathrm{Cl}$. welchit serum was administered at once, 40,000 units being given intravenously and 60,000 units intramuscularly. Sulphapyridine was given by mouth, but was replaced by sulphathiazole on March 25 owing to extreme nausea. A further aspiration was performed on March 24, and the bacillus was still present in large numbers.

On March 25, following consultation with Mr. Fatti, treatment by injection of sodium sulphathiazole into the extrapleural cavity was started. The exudate was first removed as completely as possible and lavage of the cavity with azo-T solution performed. Sodium sulphathiazole $8 \mathrm{~g}$., dissolved in $100 \mathrm{c.cm}$. of normal saline was then injected. The process was repeated on March 29 and 31 The fluid on both these occasions was negative for $\mathrm{Cl}$. welchii and for tubercle bacilli. On March 29 the sulphathiazole content of the clear fluid obtained after autoclaving was $10 \mathrm{mg}$. per $100 \mathrm{ml}$., and on March 31, $17 \mathrm{mg}$. per $100 \mathrm{ml}$.

The patient's general condition remained surprisingly good and apart from the extreme nausea caused by the oral chemotherapy, she had no complaints. Her temperature became normal on March 26 , and remained so for the rest of her stay in hospital. The white cell count was not affected by the infection or the treatment, the total counts remaining between 7,600 and 8,200 per c.mm., and the differential counts being within normal limits. Fluid gradually reaccumulated in the extrapleural space, and aspiration was again performed on May 4, when the resulting thin, slightly blood-stained, straw-coloured fluid contained only degenerate polymorphs, but no organisms.

The patient was discharged from hospital on May 8, 1943, and has since attended for two further aspirations-in June and July. On both occasions the fluid was thin and sterile.

My acknowledgments are due to Dr. J. N. Deacon, Medical Director,
Redhill County Hospital, for permission to publish this paper, and to Dr. A. S. Redhill County Hospital, for permission to publish
Hall and Mr. L. Fatti for advice on treatment.

MARY G. TATE, M.D.

Assistant Medical Officer. Redhill County Hospital, Edgware. 